$195+25 \mathrm{pg} / \mathrm{ml}$ for adult females. The difference between these 2 levels was significant $(p<0.05)$ and levels in both males and females were significantly $(p<0.05)$ higher than in the children. In 9 of the 12 children the level of testosterone in saliva was undetectable, with values falling below the sensitivity of the assay $(108 \mathrm{pg} / \mathrm{ml})$. Salivary levels of testosterone averaged $124 \pm 7 \mathrm{pg} / \mathrm{ml}$ for the remaining 3 children. The direction of age and sex differences in the concentration of testosterone in saliva are consistent with the known differences in serum testosterone levels. The sex difference in serum testosterone, however, is greater than that for testosterone in saliva. Serum testosterone levels in women do not vary with the stage of the menstrual cycle and average $400 \mathrm{pg} / \mathrm{ml}^{15}$; in men serum testosterone levels are in the range of 5.0-6.5 $\mathrm{ng} / \mathrm{ml}^{16}$. It appears that in women the levels of testosterone in saliva are about one half those in serum while in men they are less than one tenth of the serum levels. It is possible that transport of testosterone from blood to saliva is a factor limiting the levels that can be achieved in saliva.

We observed that salivary levels of testosterone varied considerably with time of day in the adult male (Figure). In both subjects, levels were highest between 07.00 and $08.00 \mathrm{~h}$ and then gradually declined throughout the day reaching a low at $22.00 \mathrm{~h}$. A circadian rhythm in serum testosterone in men is well documented ${ }^{17-19}$ with peak levels in early morning and lowest levels in late evening. Our data on testosterone levels in saliva suggest a similar circadian thythm.

The physiological role of testosterone in the saliva is not clear. It could affect cells of the oral mucosa and studies of testosterone effects on these cells must take into account the fact that the hormone may be available both from the blood and from the saliva.
Of possible importance is the potential clinical value of using testosterone levels in saliva to assess the endocrine status of a patient with respect to testosterone. In serum, testosterone is bound to a testosterone binding protein with only about $2 \%$ of the testosterone being free. Of the total testosterone in serum, only the free testosterone is metabolically active. If it is assumed that the free testosterone enters salivary gland cells and eventually appears in saliva either free or bound to a protein, then the levels of testosterone in saliva may be indicative of the availability of testosterone to other tissues in the body. This information would be far more useful than the measurement of total testosterone in serum which is not necessarily related to the testosterone available to target cells. Since only $2 \%$ of testosterone on average is available to cells at any particular time, subtle changes in binding capacity of the binding globulin and subsequent changes in free testosterone can have profound effects. The procedures required for measurement of free testosterone and binding capacity in serum are too complex and time consuming to be used as a routine clinical test. The possibility that radioimmunoassay determination of testosterone in a sample of saliva. will yield equivalent information is worthy of investigation.

15 A. Valette, B. Seradour and J. Boyar, J. clin. Endocr. Metab. 40,160 (1975).

16 J. D. Wrlson, in Handbook of Physiology, Section 7: Endocrinology (Eds. R. O. Greep and E. B. Astwood; Amer. Physiol. Soc., Washington, D.C. 1975), vol. 5, p. 491.

17 C. Faiman and J. S. D. Winter, J. clin. Endocr. 33, 186 (1971).

18 R. M. Rose, L. E. Kreuz, J. W. Holaday, K. J. Sulak and C. E. Johnson, J. Endocr, 54, 177 (1972).

19 P. H. Rowe, G. A. Lincoln, P. A. Racey, J. Lehane, M. J. Stephenson, J. C. Shenton and T. D. Glover, J. Endocr. 61, 63 (1974).

\title{
The Influence of Somatostatin on Drug-Induced Prolactin Release in the Monkey ${ }^{1}$
}

\author{
R. R. Gala, M. G. Subramanian, Judith A. Peters and S. Jaques, JR. ${ }^{2}$
}

Department of Physiology, Wayne State University School of Medicine, 540 E. Canfield Avenue, Detroit (Michigan 48201, USA), 20 January 1976.

Summary. The infusion of linear somatostatin did not block prolactin release induced by either perphenazine, TRH or serotonin. Somatostatin infusion, however, potentiated prolactin release induced by perphenazine and TRH but not that induced by serotonin.

A polypeptide hormone which inhibits growth hormone release has recently been isolated and characterized from the hypothalamus ${ }^{3}$. This hormone, called somatostatin (SRIF), can block not only basal secretion of growth hormone ${ }^{4}$ but also that provoked by drugs ${ }^{5}$, sleep $^{6}$ and hypoglycemia ${ }^{7}$. Somatostatin's inhibitory action on pituitary hormone release does not appear to be entirely specific for growth hormone since it has been reported to suppress the TRH-induced TSH release but not the basal levels of $\mathrm{TSH}^{7,8}$. It also inhibits the secretion of both glucagon and insulin ${ }^{4,9}$. Somatostatin appears to have little influence on basal levels of prolactin in

1 Supported in part by NIH General Research Support Grant No. RR5384 to Wayne State University School of Medicine and by NIH Research Grant No. HDO7722.

2 The authors wish to express their appreciation to Mrs. CYNTHA VAN DE WALLE for her outstanding technical assistance in the performance of the prolactin RIA and the statistical analyses. We also appreciate receiving linear somatostatin from Dr. R. MAKINENI, Bachem Inc., Marina Del Ray, California, USA and from Dr. N. H. Granr, Wyeth Laboratories, Philadelphia, Pa. USA. We would like to thank Abbott Laboratories, North Chicago, Ill. USA for the gift of TRH and the Schering Corp., Bloomfield, N.J. USA for the gift of perphenazine.

3 P. Brazeau, W. Vale, R. Burgus, N. Ling, M. Butcher, J. Rivier and R. Guillemin, Science 179, 77 (1973).

${ }^{4}$ S. S. C. Yen, B. L. Lasley, C. F. Wang, H. Leblac and T. M. Siler, Recent Progr. Horm. Res. 31, 321 (1975).

5 Y. Kato, K. Chimara, S. Ohgo and H. Imura, Endocrinology 95, 1608 (1974).

${ }^{6}$ D. C. Parker, L. G. Rossman, T. M. Stler, J. Rivier, S. S. C. YeN and R. Guillemin, J. clin. Endocr. Metab. 38, 496 (1974).

7 R. Hall, G. M. Besser, A. V. Schally, D. H. Coy, D. Evered, D. J. Goldie, A. J. Kastin, A. S. McNeilly, C. H. Mortimer, C. Phenekos, W. M. G. Tunbridge and D. Weightman, Lancet 2, $581(1973)$

8 T. M. Siler, S. S. C. Yen, W. Vale and R. Guillemin, J. clin. Endocr. Metab. 38, 742 (1974).

9 D. L. Curry, L. L. Bennett and C. H. Li, Biochem. biophys. Res. Commun. 58, 885 (1974). 
$\operatorname{man}^{2,10}$. In clinical situations, however, in which high levels of both growth hormone and prolactin were observed, SRIF suppressed both hormones ${ }^{11}$. It was suspected, then, that SRIF might be capable of suppressing elevated prolactin levels while having little to no effect on basal levels. To answer this, monkeys were perfused with SRIF and an increase in prolactin was induced using either perphenazine, thyrotropin releasing hormone (TRH), or serotonin.

Materials and methods. 4 female monkeys weighing between 3.1 and $5.2 \mathrm{~kg}$ were used in this study; 2 monkeys were rhesus (Macaca mulatta) and 2 were crab eating (Macaca fascicularis). One of the fascicularis monkeys was ovariectomized 2 years prior to initiation of the experiment. All the monkeys responded in a similar manner to experimental treatment although the magnitude of response varied considerably among animals. All drug injections were replicated at least twice in a random fashion at weekly intervals for each monkey. In this way animal to animal variability could be removed using a three-way analysis of variance ${ }^{12}$; all statistical comparisons between groups were made using this analysis with computer assistance.

Linear SRIF was administered i.v. as a $100 \mu \mathrm{g}$ bolus immediately after the animals were anesthesized with ketamine $(20 \mu \mathrm{g} / \mathrm{kg})$ followed by a total of $200 \mu \mathrm{g}$ infused continuously over a period of $60 \mathrm{~min} .15 \mathrm{~min}$ after the initial bolus of SRIF the following drugs were administered i.v.: perphenazine at $1 \mathrm{mg} / \mathrm{kg}$ body weight, TRH at $3.3 \mu \mathrm{g} / \mathrm{kg}$ body weight, and serotonin at $10 \mathrm{mg} / \mathrm{kg}$ body weight. Blood samples $(0.6 \mathrm{ml})$ were obtained prior to SRIF administration and every $15 \mathrm{~min}$ thereafter for $60 \mathrm{~min}$. The blood was allowed to clot at room temperature and the prolactin content of the serum determined by a human prolactin radioimmunoassay system ${ }^{13}$. Serum from rhesus monkeys at 3 dilutions was parallel with the human prolactin standard as reported previously for serum from the crab eating monkey ${ }^{14}$.

Results. The continuous infusion of SRIF resulted in a slight but statistically significant $(p<0.01)$ increase in serum prolactin when compared to saline infusion alone
(Figure). Somatostatin had no effect on blocking provoked prolactin release by the 3 drugs examined, however it significantly potentiated the response of perphenazine and TRH on the release of prolactin $(p<0.01)$. The combination of somatostatin plus serotonin did not alter the prolactin-releasing action of serotonin alone.

Discussion. The data presented indicate that SRIF does not suppress either basal levels of serum prolactin or provoked levels. CHEN et al. ${ }^{15}$ observed that the sucklinginduced release of prolactin was not blocked by SRIF while there was a suppression of the growth hormone release. The suckling-induced increase in serum prolactin of animals receiving SRIF was somewhat higher than that of animals receiving saline and suckled, but the difference was not statistically significant. Others observed that the chlorpromazine-induced increase in serum prolactin in the rat was not blocked by SRIF and was in fact slightly higher than that of chlorpromazine alone ${ }^{16}$. DAvis ${ }^{17}$, however, noted that in lambs the TRH-induced increase in serum prolactin appeared to be suppressed by SRIF infusion although the author admitted that the data was not conclusive. The available evidence suggests that the ability of SRIF to decrease the elevated plasma prolactin in certain clinical situations ${ }^{11}$ is not because of the elevation of prolactin per se but rather is due in all probability to a change in the hypothalamic-pituitary axis.

10 T. M. Siler, G, VandenBerg, S. S. C. Yen, P. Brazeau, W. Vale and R. Guildemin, J. clin. Endocr. Metab. 37, 632 (1973). 11 S. S. C. Yen, T. Siler and G. W. DeVane, New Engl. J. Med. 290,935 (1974).

12 B. J. WINER, Statistical Principles in Experimental Design (McGrawHill Book Co., New York 1971), p. 514.

13 Y. N. Sinha, F. W. Setby, U. J. Lewis and W. P. Vanderlaan, J. clin. Endocr. Metab. 36, 509 (1973).

${ }^{14}$ R. R. Gala and S. Jaques, JR., Endocr. Res. Commun. 2, 95 (1975).

15 H. J. Chen, G. P. Muelter and J. Meites, Endocr. Res. Commun. 1, $283(1974)$.

${ }^{16}$ S. Sawano, Y, Baba, T. Kokubu and Y. Ishizuka, Endocr. jap. 21, $399(1974)$

${ }^{13}$ S. L. Davis, J. Animal Sci. 40, 911 (1975).
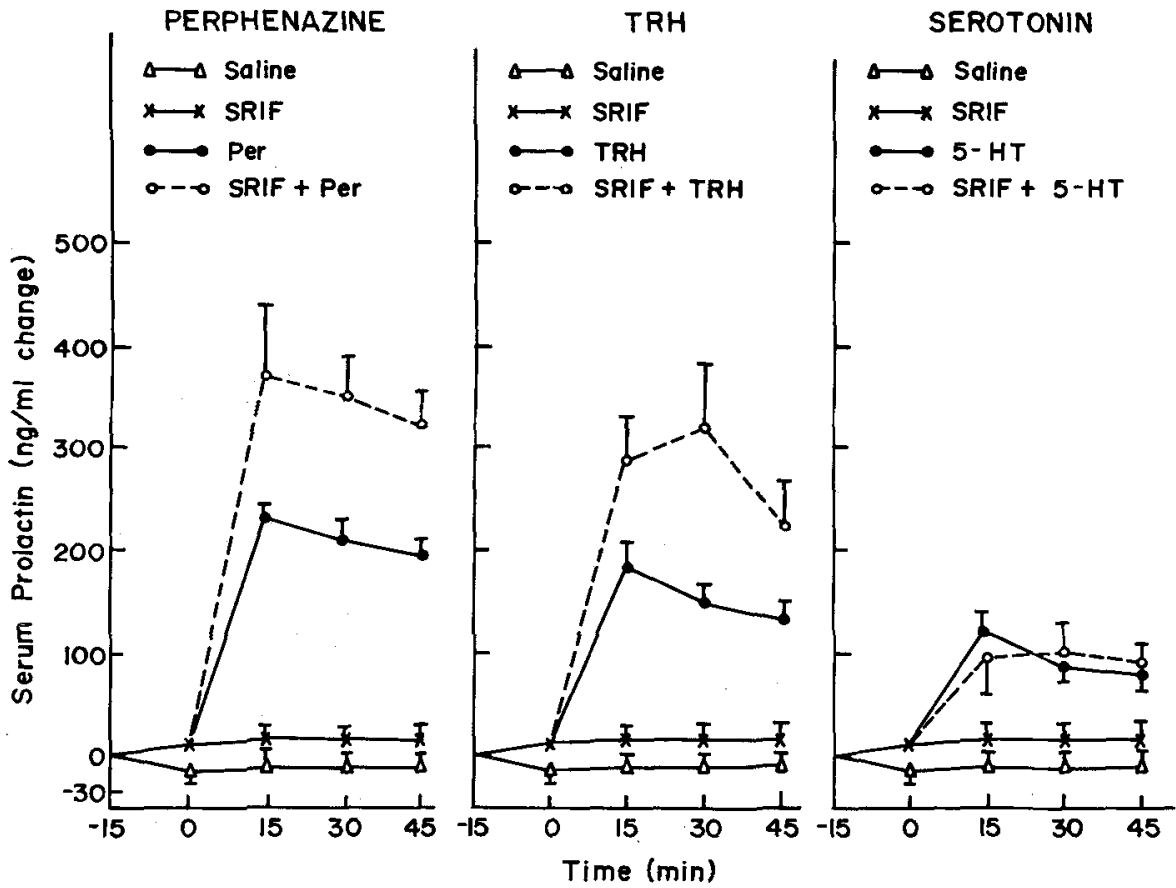

The influence of somatostatin (SRIF) on induced prolactin release. Vertical lines represent the SEM. Linear SRIE was initially administered i.v. as a $100 \mu g$ bolus immediately after the -15 min blood sample followed by continuous infusion of $200 \mu \mathrm{g}$ over the next 60 min. Drugs were administered i.v. immediately after 0 min blood sample at the following dosages: perphenazine (Per), $1 \mathrm{mg}$ / $\mathrm{kg}$ body weight; thyrotropin releasing hormone (TRH), $3.3 \mu \mathrm{g} / \mathrm{kg}$ body weight; and serotonin creatinine sulfate $(5-\mathrm{HT}), 10 \mathrm{mg} / \mathrm{kg}$ body weight. Statistically significant differences are presented in the text. 
The potentiating action of SRIF on perphenazine and TRH-induced prolactin release was an unexpected observation. It does not appear to be a simple amplification of the effect of SRIF alone since no potentiating effect on serotonin-induced prolactin release was observed. It was possible that SRIF interacted with the anesthetic ketamine to give the potentiating action. This is believed, however, not to be the case since the serotonin response was not altered and since some potentiating action of SRIF in unanesthetized animals has been reported for provoked prolactin release ${ }^{15,16}$. The magnitude of potentiation in these reports, however, was not as great as we observed here. We believe that the answer lies in the mechanism of the perphenazine and TRH-induced prolactin release since we have observed a similar potentiating effect of atropine on perphenazine-induced prolactin release $^{18}$. An explanation of the potentiation of SRIF on provoked prolactin release appears to be complex and must be deferred until the mechanism of action of SRIF and of prolactin release are better understood.

18 R. R. Gala, M. G. Subramanian, J. A. Peters and S. Jaques, jr. Horm. Res., in press.

\section{Monoamine Oxidase Localization in the Ependyma and Infundibular Recess in the Catfish Clarias batrachus and its Probable Significance}

A. G. Sathyanesan and K. P. Joy ${ }^{1}$

Surgical Research Laboratory, Institute of Medical Sciences, Banaras Hindu University, Varanasi-5 (India), 14 October 1975.

Summary. The presence of monoamine oxidase (MAO) in the cerebrospinal fluid (CSF) and MAO positive tracts bridging the CSF and the subependyma strongly suggest the involvement of CSF in the neuroendocrine control of hypophysial function.

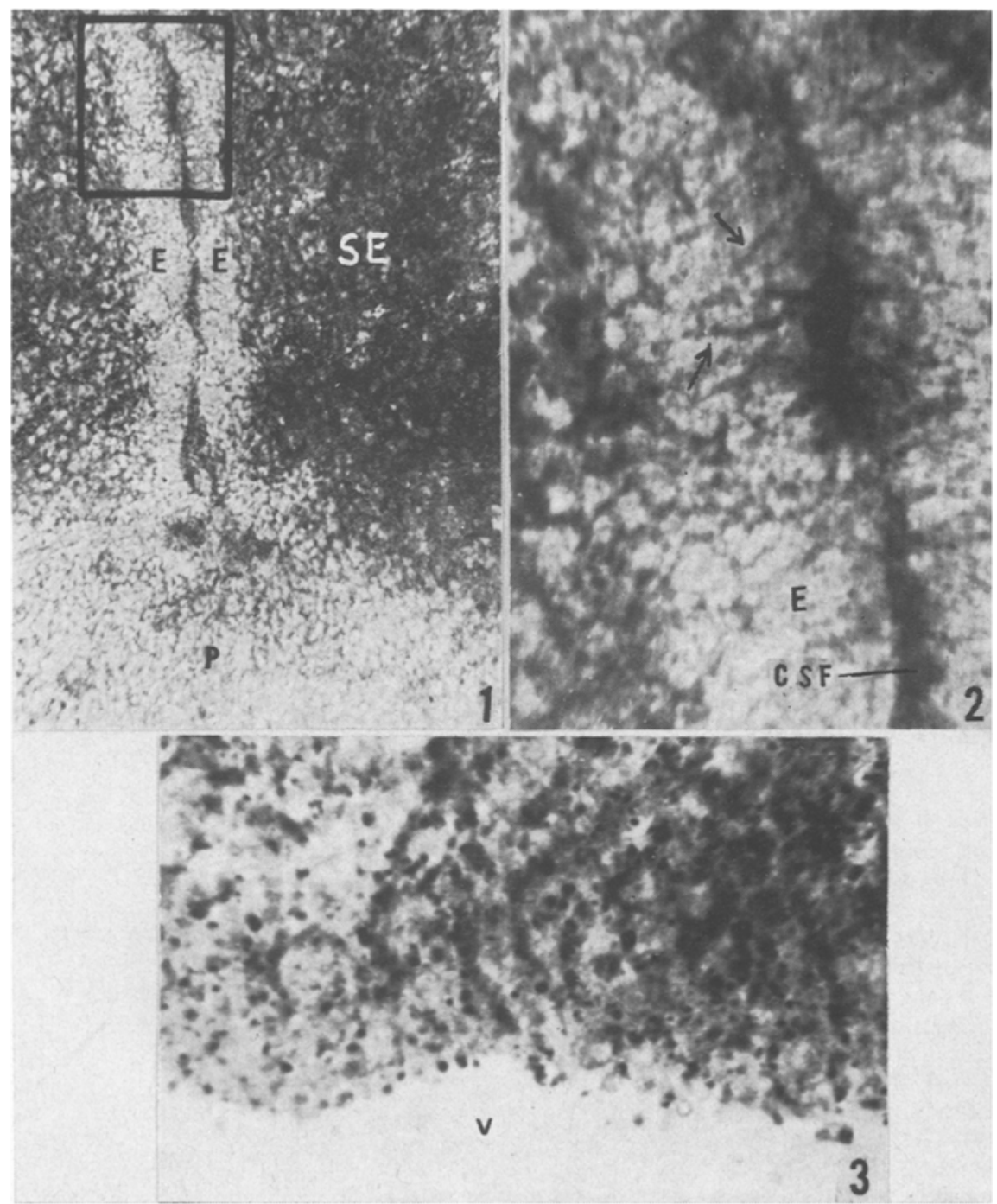

Fig. 1. Frontal section showing subependyma (SE), ependyma (E), 3 rd ventricle (V) and a part of the pituitary $(\mathrm{P}) . \times 180$.

Fig. 2. Inset of lïigure 1, enlarged to show MAO positive tracts (arrows) bridging MAO filled 3rd ventricle and subependyma. $\times 600$.

Fig. 3. Part of the subependyma and ependyma in the anterodorsal region of the infundibular recess, $\times 600$. 